This item was submitted to Loughborough's Research Repository by the author.

Items in Figshare are protected by copyright, with all rights reserved, unless otherwise indicated.

\title{
An electrochemical microactuator based on highly textured LiCoO2
}

PLEASE CITE THE PUBLISHED VERSION

http://dx.doi.org/10.1016/j.snb.2012.08.079

PUBLISHER

(c) Elsevier

VERSION

AM (Accepted Manuscript)

PUBLISHER STATEMENT

This work is made available according to the conditions of the Creative Commons Attribution-NonCommercialNoDerivatives 4.0 International (CC BY-NC-ND 4.0) licence. Full details of this licence are available at: https://creativecommons.org/licenses/by-nc-nd/4.0/

\section{LICENCE}

CC BY-NC-ND 4.0

\section{REPOSITORY RECORD}

Zhang, Hongtao, and Patrick S. Grant. 2015. "An Electrochemical Microactuator Based on Highly Textured Licoo2". figshare. https://hdl.handle.net/2134/17747. 


\title{
An electrochemical microactuator based on highly textured $\mathrm{LiCoO}_{2}$
}

Hongtao Zhang ${ }^{*}$ and Patrick S. Grant

Department of Materials, University of Oxford, Parks Road, Oxford OX1 3PH, UK

\begin{abstract}
In this paper we demonstrate a novel electrochemical actuator based on an array of micro-pillars of intercalation compound $\mathrm{LiCoO}_{2}$ with induced crystallographic texture (Lotgering factor $f=0.96$ ) to enhance actuation strain. The highly textured $\mathrm{LiCoO}_{2}$ posts were fabricated by hot-press sintering and subsequent dicing, and the contrived texture facilitated both electrochemical lithiation and resulting actuation strain in the longitudinal direction. Compared with traditional actuator materials, such as piezoceramics, the micro-pillar array of $\mathrm{LiCoO}_{2}$ showed an almost one order higher actuation strain $(1.2 \%)$ at a low applied voltage $(<5 \mathrm{~V})$. The conceptual demonstration outlined in this paper provides a foundation for the design and application of intercalation compounds as novel smart materials.
\end{abstract}

Key words: Electrochemical actuator, intercalation compound, texture, $\mathrm{LiCoO}_{2}$

* Corresponding author. Tel.: +44 1865283714; fax: +44 1865848785.

E-mail address: hongtao.zhang@materials.ox.ac.uk 


\section{Introduction}

Actuators are based on materials that change shape and dimension when an external stimulus is applied [1]. They are crucial for such diverse needs as robotics, prosthetic devices, sonar projectors, medical devices, microscopic pumps, microelectromechanical systems and so forth. At the sub-centimetre size, actuators make use of piezoelectric, pyroelectric, electrostrictive, magnetostrictive, piezoresistive, electroactive, and other effects. Piezoceramics are the most dominant microactuator materials today due to their extremely fast response. However, high modulus piezoceramics require rather high voltages (several hundreds or thousands of volts) to operate and low modulus ferroelectric ceramics have reduced force. The strains produced by a piezoelectric actuator are $0.1-0.2 \%$, even for "high" strain polycrystalline lead perovskites [2]. Shape memory alloys exhibit the highest actuation energy density and can deliver a strain of up to $8 \%$ [1], but generally require careful temperature control for their operation. Conductive polymers, typified by polypyrrole and polyaniline, are technologically attractive due to their low operating voltage (1 V or less), high force, moderate strain and controllability. In particular, polypyrrole actuators can generate a strain of $1-3 \%$ under electro-chemical excitation and the forces generated are $10^{2}-10^{3}$ times greater than skeletal muscle. But the relationship between input electrical energy and mechanical output has yet to be fully understood and efficiency currently tends to be low at around 1\% [3]. Other smart materials, such as electrostrictive and magnetostrictive actuators require high operating voltages or magnetic fields, and overall no microactuator material/effect combination provides idealised behaviour and each has compromised behaviour in at least one aspect. 
Recently, electrochemical actuators have attracted attention as they provide the potential for actuation performance in some areas. For example, carbon single-walled nanotubes (SWNTs) can be used as electrochemical actuators when placed in an electrolyte, delivering stresses $\sim 10^{2}$ times greater than those generated by natural muscle, along with higher strains of up to $\sim 1 \%$ at very low operating voltage $(<10 \mathrm{~V})$ [4]. However, the chief drawback of electrochemical actuators is that they are based on transport-limited mechanisms for actuation, and as such is intrinsically slower than piezoelectrics and magnetostrictors.

Electrochemical actuators can be operated by different mechanisms, such as the electrolysis of an aqueous electrolyte solution [5], solid/gas reaction [6], and quantum chemical and double-layer electrostatic effects [4]. The intercalation compounds empolyed in lithium ion rechargeable batteries are well known to undergo remarkable reversible volume change during intercalation and de-intercalation. This is a major concern for Li-ion battery application because volume change of electrode materials leads to pulverization and degrades the battery performance [7]. However, this effect can be utilized to produce electrochemically-induced strain. So far there are only few reports on intercalation compound-based electrochemical actuators. Takada et al. [8] demonstrated electrochemical actuation using silver vanadium bronze but not against an applied stress. Gu et al. [9] reported a strain of up to $0.21 \%$ and generated stress of up to 5.9 $\mathrm{MPa}$ using $\mathrm{V}_{2} \mathrm{O}_{5}$ nanofibre sheets.

Koyama et al.[10,11] proposed that electrochemical actuators based on intercalation compounds could have the potential for extremely high actuation-energy density and force because of their large reversible crystallographic strains and intrinsically high 
elastic moduli. By using highly orientated pyrolitic graphite (HOPG) posts fabricated by laser micro-machining, Koyama et al. made an microactuator with an actuation energy density as high as $6700 \mathrm{~kJ} / \mathrm{m}^{3}$, which was more than $10^{2}$ times greater than any existing electrically operated micro-actuation mechanism, and was comparable to shape memory alloys. Their microactuator exhibited a strain of $6.7 \%$ and $0.7 \%$ against a $10 \mathrm{MPa}$ and $200 \mathrm{MPa}$ "blocking" stress, respectively. A higher rate capability was further demonstrated in a multilayer construction, similar to prismaticform lithium ion batteries.

In this paper, we present a microfabricated electrochemical microactuator capable of achieving high actuation strain against an applied stress of $1 \mathrm{MPa}$ at low operating voltage by using highly textured $\mathrm{LiCoO}_{2}$ in an array of micro-pillars. The potential applications for intercalation compound based electrochemical microactuators are discussed.

\section{Experimental}

\section{1 Microactuator design}

The electrochemical cells in the prismatic configurations found in commercial Li-ion batteries have two features that must be addressed if Li-ion intercalation/deintercalation strains are to be considered for actuation purposes: (1) an applied load to the actuator, or blocking stress, will squeeze the liquid organic electrolyte from between the Li-based cathode and graphite-based anode; and (2) the induced strain will be isotropic since the electrode materials are in the form of randomly arranged 
powders, which means the strain and energy density of a uniaxial actuator stroke cannot be fully optimized. For the first problem, even if an impregnated solid polymer is used to hold the electrolyte (a "Li-polymer" battery), the polymer modulus is too low to offer any useful load carrying capacity.

Our approach to the first problem is overcome by adopting a microactuator design with four square arrays of load-bearing $\mathrm{LiCoO}_{2}$ posts made by micromachining, as shown schematically in Fig. 1. Each array of pillars consisted of $5 \times 5=25$ square posts, each of which was of $0.4 \mathrm{~mm}$ width and $1 \mathrm{~mm}$ height. Compared with Koyama's single post array design [10], our set of four post arrays provides the ability to distribute load over a larger area. In order to integrate these $\mathrm{LiCoO}_{2}$ post arrays into a microactuator and as shown in Fig. 1, a number of sub-assemblies with a gasket configuration for the anode (graphite) coated on copper foil, polymer separator and cathode current collectors (Ag paste) was used in which the gasket materials sit on the base of $\mathrm{LiCoO}_{2}$ and then surround the $\mathrm{LiCoO}_{2}$ posts. This planar arrangement is then suitable for a pouch cell configuration, as described later.

$\mathrm{LiCoO}_{2}$ adopts a layered structure having rhombohedral symmetry with space group R $\overline{3} \mathrm{~m}$. The structure of $\mathrm{LiCoO}_{2}$ consists of layers of edge-sharing lithium and cobalt octahedra stacked alternatively between $\mathrm{ABCABC}$ cubic-close-packed oxygen arrays. Driven by increasing electrostatic repulsion between $\mathrm{CoO}_{2}$ slabs as a result of lithium removal during charging, anisotropic structural changes in $\mathrm{Li}_{x} \mathrm{CoO}_{2}$ occur upon lithium de-intercalation, where the strain in the $c_{\text {hex }}$ axis is much greater than the strain in $a_{\text {hex }}$ axis [7]. Since the largest strain is along $c$-axis of the $\mathrm{LiCoO}_{2}$ lattice [12] and the fastest $\mathrm{Li}^{+}$diffusion occurs along $a-b$ plane of the $\mathrm{LiCoO}_{2}$ lattice [13], it is 
important to explore a design which can fully take advantage of crystal anisotropy for actuation. Therefore, we fabricated the post arrays with a configuration in which the more responsive $c$-axis orientates preferentially to the actuation direction along the posts by contriving highly textured $\mathrm{LiCoO}_{2}$. In view of the fact that the $\mathrm{LiCoO}_{2}$ grains exhibit a plate-like morphology due to its layered crystallographic structure [14], we induce the formation of the required strong crystallographic texture in the $\mathrm{LiCoO}_{2}$ by a carefully manipulated hot-press sintering route.

\subsection{Preparation of bulk textured $\mathrm{LiCoO}_{2}$}

As-supplied lithium cobalt oxide $\left(\mathrm{LiCoO}_{2}\right.$, Sigma-Aldrich, UK) powders with stated purity of $99.8 \%$ were ball milled for $72 \mathrm{~h}$ and then sieved to under $250 \mu \mathrm{m}$. The powders were consolidated in a graphite die and sintered at $950^{\circ} \mathrm{C}$ for $5 \mathrm{~h}$ under a uniaxial applied pressure of $20 \mathrm{MPa}$ under vacuum. The full details of the preparation of the highly textured $\mathrm{LiCoO}_{2}$ were described in a previous publication [15].

\subsection{Fabrication and packaging of the microactuator}

Bulk sintered $\mathrm{LiCoO}_{2}$ discs with a diameter of $33 \mathrm{~mm}$ were firstly cut to a rectangle with $x-y$ dimensions $20 \times 20 \mathrm{~mm}$ and thickness $\sim 3 \mathrm{~mm}$ by using a diamond wafer blade. Then $\mathrm{LiCoO}_{2}$ post arrays which will become the cathode in the microactuator cell were machined using an accurate dicing machine (MicroAce-series 3, Loadpoint Ltd, Swindon, UK). Fig. 2 shows side view of $\mathrm{LiCoO}_{2}$ post arrays fabricated by dicing. The posts were $400 \mu \mathrm{m}$ square and $1 \mathrm{~mm}$ in height. Compared with laser micromachining used by Koyama et al. [10], dicing used in current work is a much 
more cost-effective method. In addition, all posts here were parallel sided without any taper, in contrast to micromachined HOPG. The base "plinth" of the $\mathrm{LiCoO}_{2}$ pillars was then coated with $\mathrm{Ag}$ paste (Johnson Matthey, E1100) and fired at $800^{\circ} \mathrm{C}$ for 30 min. An anode slurry was fabricated by mixing the graphite powder (particle size $<20$ $\mu \mathrm{m}$, Sigma-Aldrich, UK) with 10wt \% poly-vinylidene fluoride (Sigma-Aldrich, UK) in $\mathrm{N}$-methyl pyrrolidone solution (Sigma-Aldrich, UK). The slurry was cast onto a $\mathrm{Cu}$ foil and dried in a vacuum oven at $120^{\circ} \mathrm{C}$ for $12 \mathrm{~h}$ to form the graphite gasket. Then, the graphite gasket and polymer separator was placed sequentially around the $\mathrm{LiCoO}_{2}$ post arrays. The microactuators were then placed in pouches formed from aluminumpolymer film foil laminates (Fisher Scientific UK Ltd) and injected with a standard lithium-ion battery electrolyte $\left[1 \mathrm{M} \mathrm{LiClO}_{4}\right.$ solution dissolved in a 1:1 (by volume) mixture of ethylene carbonate and dimethyl carbonate, Sigma-Aldrich, UK] in an Arfilled glove box, and the pouch was finally sealed using a hot plate press.

\subsection{Microstructural characterization}

$\mathrm{X}$-ray diffraction $(\mathrm{XRD})$ using $\mathrm{Cu} \mathrm{K \alpha}$ radiation was performed at room temperature in a Siemens D5000 diffractometer to characterise the crystal structure of the $\mathrm{LiCoO}_{2}$. Bulk textured $\mathrm{LiCoO}_{2}$ for scanning electron microscope (SEM) study was polished and then thermally etched at $850^{\circ} \mathrm{C}$ for $15 \mathrm{~min}$ and then studied in a JEOL 840A SEM operating an accelerating voltage of $15 \mathrm{kV}$.

\subsection{Performance testing}


In order to measure the extension/contraction of the $\mathrm{LiCoO}_{2}$ posts during charging/discharging, we designed an in-situ non-contact displacement monitoring system based on a capacitance displacement sensor (Nanosensor NXD1-SI, Queensgate Instruments Ltd, UK). Fig. 3 shows the apparatus for the performance testing of the microactuator. The packaged microactuator was held flat on a cast iron stage. A constant stress of $1 \mathrm{MPa}$ was applied to the packaged microactuator by putting a weight on the top of the microactuator, where stress was calculated by dividing the load by total area of the four sets of $5 \times 5$ post arrays. There were two electrodes for the capacitance displacement sensor: one was tightly fixed on the top of weight; the other was positioned on the underside of the upper steel beam. The steel beam was supported on an Invar steel to minimise any ambient thermal fluctuation and associated thermal expansion effects. The microactuator was charged or discharged using a battery charger (Ministat potentiostat, H.B. Thompson and Associates, Newcastle, UK). The thickness change of the entire microactuator package along the direction of applied stress during charging/discharging was then precisely measured by detecting the gap distance between the two electrodes of the sensor by a change in capacitance. The working range of the sensor was $0-250 \mu \mathrm{m}$ with a resolution of $1 \mathrm{~nm}$.

\section{Results and discussion}

\subsection{Microstructural characterization}

XRD patterns from the $\mathrm{LiCoO}_{2}$ disc surfaces perpendicular to the hot-pressing direction are shown in Fig. 4, and are compared with a pattern from the randomly 
oriented as-supplied powder. The diffraction peaks were matched and indexed according to the diffraction data of pure $\mathrm{LiCoO}_{2}$ (JCPDF No. 44-145). The materials were all single-phase within the sensitivity of the technique. For the powdered sample, the highest intensity reflection was (003) followed by (101) and (104) reflections [Fig. 4(a)], while for the pressed $\mathrm{LiCoO}_{2}$ with the surface perpendicular to the pressing direction, there were reflections of the type $(00 l)$ where $l=3,6,9,12$, only [Fig. 4(b)]. The grains in the bulk $\mathrm{LiCoO}_{2}$ were strongly oriented along the $c$-axis of the $\mathrm{LiCoO}_{2}$ lattice. The degree of texture can be estimated using the Lotgering factor $f$ which was determined using the XRD data in the $2 \theta$ range of $15^{\circ}-85^{\circ}$ according to [16]:

$$
f=\left(p-p_{0}\right) /\left(1-p_{0}\right)
$$

where $p=\sum_{l} I(00 l) / \sum_{h k l} I(h k l), \sum_{l} I(00 l)$ and $\sum_{h k l} I(h k l)$ were the sums of the intensities of $(00 l)$ and $(h k l)$ reflections respectively, and $p_{0}$ is the value of $p$ for a randomly oriented sample, taken in this study as the as-supplied powder. $f$ varies from 0 (nonoriented) to 1 (completely oriented) and can be used as a measure of the grain orientation. The $\mathrm{LiCoO}_{2}$, as intended, had $f=0.96$ confirming a very high degree of crystallographic texture.

Figure 5 shows SEM images of the textured $\mathrm{LiCoO}_{2}$ ceramics. The surface perpendicular to the hot-pressing direction [Fig. 5(a)] indicated that the $\mathrm{LiCoO}_{2}$ grains developed a plate-like shape, while at the surface parallel to the hot-pressing direction [Fig. 5(b)], the short axis of all plate-like grains were aligned strongly to the pressure direction. 


\subsection{Electrochemical actuation of the $\mathrm{LiCoO}_{2}$ pillar array}

Electrochemical actuation of the $\mathrm{LiCoO}_{2}$ microactuator against a constant applied stress $(1 \mathrm{MPa})$ under two different charging/discharging protocols is shown in Fig. 6. Fig. 6(a) illustrates the results for microactuator tested under constant voltage $(\mathrm{CV}=$ $4.2 \mathrm{~V})$ charge and constant current $(\mathrm{CC}=0.2 \mu \mathrm{A})$ discharge. The highest actuation strain of the $\mathrm{LiCoO}_{2}$ post arrays was obtained under a $\mathrm{CV}$ testing protocol, which is consistent with the results of the earlier HOPG microactuator [10]. The expansion strain of $\mathrm{LiCoO}_{2}$ microactutor first increased with $\mathrm{CV}$ charging time and then reached a plateau of $\sim 1.2 \%$ in the time interval from $8.9 \mathrm{hr}$ to $10.1 \mathrm{hr}$, as indicated in Fig. 6(a). Subsequently there was a slight decrease in expansion strain up to $12 \mathrm{hr}$. The maximum expansion of the $c$-axis in $\mathrm{LiCoO}_{2}$ during charging from $\mathrm{LiCoO}_{2}$ to $\mathrm{Li}_{0.5} \mathrm{CoO}_{2}$ has been reported to be in the range $2.4-2.6 \%$ according to ex-situ and insitu XRD [17]. Considering that the $\mathrm{LiCoO}_{2}$ posts were highly textured with $c$-axis aligned with the post long axis, the measured expansion strain of $1.2 \%$ in the present work is reasonable, and almost one order higher than the strain $(0.1-0.2 \%)$ provided by piezoceramics. The mechanical work (stress $\times$ strain) delivered by the $\mathrm{LiCoO}_{2}$ posts during electrochemical expansion was $12 \mathrm{kJm}^{-3}$.

A plateau of expansion strain and then a continuous decrease in expansion strain over time during CV charging has been reported for commercial lithium ion batteries [18, 19]. However, the mechanism for the slight fade of expansion strain is not well understood. Because our microactuator was sealed in a pouch, it was impractical to observe the actuation response of each individual micropillar during charging/discharging. But we suppose that the decrease in the expansion strain of 
$\mathrm{LiCoO}_{2}$ microactuator during $\mathrm{CV}$ charging might derive from an expected nonuniform de-intercalation level between interior $\mathrm{LiCoO}_{2}$ posts (far from the graphite anode) and external $\mathrm{LiCoO}_{2}$ posts (close to anode) intrinsic to the pillar array configuration. Those posts that were in centre region of the $5 \times 5$ array experienced a lower extent of de-intercalation, while the external $\mathrm{LiCoO}_{2}$ posts that were close to the graphite gasket anode had a higher degree of de-intercalation and thus provided a larger expansion strain and consequently carried most of load. Thus, the expansion of interior $\mathrm{LiCoO}_{2}$ posts may not synchronously follow that of the external $\mathrm{LiCoO}_{2}$ posts, and the slight decrease in expansion strain during extended CV charging may result from relaxation of the strain in external $\mathrm{LiCoO}_{2}$ posts and a gradual shift to more uniform de-intercalation behaviour.

We have considered different pillar array configurations with few pillars in each array to reduce the relaxation of strain. However, smaller pillar arrays would require increasingly delicate, hard to align, and perhaps impractical copper foil gaskets (Fig. 1) also to be produced in order to reduce the lithium ion diffusion distance between cathode and anode. Nevertheless, it does not seem unlikely that future work and other fabrication approaches may well find alternative, more practical approaches to this aspect. For the current work, a pillar array configuration with $5 \times 5$ posts was selected for practical demonstration.

The microactuator was discharged in CC mode at $13.7 \mathrm{hr}$. There was an immediate decrease in the voltage of the microactuator from $4.2 \mathrm{~V}$ to $2.97 \mathrm{~V}$ once the state of microactuator was switched from charging to discharging due to the IR drop related to the equivalent series resistance of the overall electrochemical cell. The voltage of the 
microactuator slowly decreased in the period $13.7 \mathrm{hr}$ to $32 \mathrm{hr}$ and then dramatically reduced after $32 \mathrm{hr}$. The expansion strain was almost unchanged at the beginning of discharging, and then the $\mathrm{LiCoO}_{2}$ posts progressively contracted and led to the progressive decrease in strain.

Fig. 6(b) shows the electrochemical actuation performance of the $\mathrm{LiCoO}_{2}$ microactuator against a constant applied stress $(1 \mathrm{MPa})$ under an alternative CC charge and $\mathrm{CC}$ discharge protocol. The $\mathrm{CC}$ charge and discharge current was $3 \mathrm{~mA}$ and $0.1 \mathrm{~mA}$, respectively. The voltage of the microactuator increased sharply from $0.02 \mathrm{~V}$ to $3.88 \mathrm{~V}$ in the first 3 minutes charging and then climbed slowly afterwards. Similar charging curves are observed in commercial Li-ion batteries [20]. The expansion strain increased almost linearly with the time, which was consistent with the actuation response of the earlier $\mathrm{HOPG}$ microactuator under $\mathrm{CC}$ charging condition [10]. Charging was terminated at $4.3 \mathrm{hr}$ once the voltage of microactuator increased to $4.20 \mathrm{~V}$, where the expansion strain was $0.055 \%$. $4.20 \mathrm{~V}$ was a preselected cut-off charging voltage for the $\mathrm{LiCoO}_{2} /$ graphite system because higher voltages can lead to cobalt dissolution induced structural instabilities and capacity fade of $\mathrm{LiCoO}_{2}$ [21], and irreversible decomposition of electrolyte [7].

The microactuator was then held at open-circuit state from $4.3 \mathrm{hr}$ to $11.7 \mathrm{hr}$. During initial open-circuit hold from $4.3 \mathrm{hr}$ to $7.4 \mathrm{hr}$, the voltage of the microactuator was near constant $(\sim 2.86 \mathrm{~V})$ and the expansion strain continually increased until a plateau region of $0.075 \%$ (marked by the arrows in Fig. 6(b)) was reached between $5.0 \mathrm{hr}$ and $7.5 \mathrm{hr}$. The microactuator started to slowly self-discharge from $2.86 \mathrm{~V}$ to $2.46 \mathrm{~V}$ after 
$7.4 \mathrm{hr}$. Accordingly, the microactuator slightly contracted. The contraction continued during $\mathrm{CC}$ discharge. Self-discharge is common problem for $\mathrm{Li}$-ion batteries, and here may also be related to chemical reaction between organic electrolyte solvent and electrode materials when the microactuator was charged for the first time [7].

One of key challenges in achieving a reasonable cycle life was to achieve robust electrical contacts for the $\mathrm{LiCoO}_{2}$ substrate, cathode current collector and microactuator terminal (conducting wire). A very good electronic contact between $\mathrm{LiCoO}_{2}$ substrate and cathode current collector was achieved using the high temperature $\left(800^{\circ} \mathrm{C}\right)$ fired $\mathrm{Ag}$ paste. The subsequent joint between $\mathrm{Ag}$ paste and conducting wire was connected by using solder, and this combination led to galvanic corrosion that progressively undermined performance on each cycle. The performance in Fig. 6 was very similar for three devices, with a maximum expansion strain reproduced to $\pm 8 \%$. Nevertheless, long term cycling behaviour should be improved by careful choice of compatible electrical joint materials with one another and the electrolyte environment, and use of protective coatings.

Actuation energy density is usually used to distinguish the capabilities of different actuator materials. The theoretical actuation-energy density is equal to $1 / 2 E \varepsilon_{\max }{ }^{2}$, where $E$ is elastic modulus and $\varepsilon_{\max }$ is the maximum free strain, i.e. the strain achieved in absence of a blocking stress. Theoretical calculations suggest $\sim 150 \mathrm{GPa}$ for the Young's modulus of $\mathrm{LiCoO}_{2}[22,23]$. The maximum expansion of $c$-axis of $\mathrm{LiCoO}_{2}$ lattice during charging from $\mathrm{LiCoO}_{2}$ to $\mathrm{Li}_{0.5} \mathrm{CoO}_{2}$ has been suggested to be $2.5 \%$ [17]. Therefore, if any difference in Young's modulus with crystallographic orientation and 
de-intercalation are ignored for the simplicity, we obtain a theoretical actuationenergy density of $\mathrm{LiCoO}_{2}$ microactuator of $\sim 47 \mathrm{MJm}^{-3}$. In practice, the $\mathrm{LiCoO}_{2}$ discs prepared by hot-press sintering easily withstood a compressive load of $100 \mathrm{MPa}$ without breakdown, while a $1.2 \%$ strain was measured under a $1 \mathrm{MPa}$ load and can be assumed as the free strain to give an actual actuation-energy density of $600 \mathrm{kJm}^{-3}$, which is 6 times that of a good lead-zirconium-titanate (PZT) piezoelectric ceramic $\left(\sim 100 \mathrm{kJm}^{-3}\right.$ from Ref 10$)$. Further accounting for the difference in specific gravity of these two materials $\left(5050 \mathrm{kgm}^{-3}\right.$ for $\mathrm{LiCoO}_{2}$ versus $7500 \mathrm{kgm}^{-3}$ for PZT [24,10]), the disparity in specific energy is even larger (one order), i.e. $118.8 \mathrm{Jkg}^{-1}$ versus $13.3 \mathrm{Jkg}^{-1}$. The major merits of the present actuation approach compared with competing technologies are summarized in Fig. 7, which is plotted after Ref 1. Figure 7 shows that the energy density of the $\mathrm{LiCoO}_{2}$ microactuator exceeded those of piezopolymer and piezoelectric ceramics.

The major disadvantage of our approach is the slow frequency because it is based on an electrochemical diffusion process. However, the dimensions of the posts here was relatively coarse for ease of processing in this proof-of-principle study. Microactuator performance could be significantly enhanced by using other microfabrication processes $[25,26]$ to achieve a much smaller pillar cross section. This type of intercalation compound based electrochemical microactuators may then find applications where relatively slow but forceful and controllable actuation is needed, such as biological or medical devices to pump and control delivery of small volumes of fluids, as well as valves, infusion pumps and other drug delivery devices [27, 28]. An interesting device topology is where two such microactuators are counter-posed to produce a reciprocating stroke, where diacharge of one actuator battery can provide 
the charge of the other, and then doubling the potential force at high energy efficiency.

\section{Conclusions}

An electrochemical actuator based on the intercalation compound $\mathrm{LiCoO}_{2}$ has been demonstrated. In order to take advantage fully of $\mathrm{LiCoO}_{2}$ crystalline anisotropy for actuation, we proposed a novel design in which highly textured $\mathrm{LiCoO}_{2}$ post arrays facilitated both electrochemical lithiation and actuation strain. The pronounced preferred orientation of the polycrystalline $\mathrm{LiCoO}_{2}$ with a high Lotgering factor $(f=0.96)$ was prepared by hot-press sintering, followed by a cost-effective dicing method. The $\mathrm{LiCoO}_{2}$ microactuator exhibited expansion during charging and contraction during discharging. The maximum actuation expansion strain of up to $1.2 \%$ was achieved during low operating voltage $(4.2 \mathrm{~V})$ charging, and was an order higher than the actuation strain of piezoceramics. The mechanical work delivered by the $\mathrm{LiCoO}_{2}$ microactuators during electrochemical expansion was $12 \mathrm{kJm}^{-3}$. The promising actuation behaviour from this preliminary $\mathrm{LiCoO}_{2}$-based microactuator design indicates that intercalation compound-based electrochemical actuators may have potential for biological or medical device applications, such as valve actuation, infusion pumps and other drug delivery devices.

\section{Acknowledgments}


This work was financially supported by the UK Engineering and Physical Sciences

Research Council under contract EP/D034256/1. The authors would like to thank Mr.

Robin Vincent for his technical skill and support.

\section{References}

[1] J. E. Huber, N. A. Fleck, M. F. Ashby, The selection of mechanical actuators based on performance indices, Proc. R. Soc. Lond. A. 453 (1997) 2185-2205.

[2] S. E. Park, T. R. Shrout, Ultrahigh strain and piezoelectric behavior in relaxor based ferroelectric single crystals, J. Appl. Phys. 82 (1997) 1804-1811.

[3] S. A. Wilson, R. P.J. Jourdain, Q. Zhang, R. A. Dorey, C. R. Bowen, M. Willander, Q. U. Wahab, M. Willander, S. M. Al-hilli, O. Nur, E. Quandt, C. Johansson, E. Pagounis, M. Kohl, J. Matovic, B. Samel, W. van der Wijngaart, E. W.H. Jager, D. Carlsson, Z. Djinovic, M. Wegener, C. Moldovan, R. Iosub, E. Abad, M. Wendlandt, C. Rusu, K. Persson, New materials for micro-scale sensors and actuators: An engineering review, Mater. Sci. Eng. R. 56 (2007) 1-129.

[4] R. H. Baughman, A. A. Zakhidov, W. A. de Heer, Carbon nanotubes-the route toward applications, Science. 297 (2002) 787-792.

[5] M W. Hamherg, C. Neagu, J.G.E. Gardeniers, D.J. Ijntema and M. Elwenspoek, An electrochemical micro actuator, in Micro Electro Mechanical Systems - IEEE Proceedings, Amsterdam, The Netherlands, 1995, 106-1 10.

[6] C. R. Neagu, J. G. E. Gardeniers, M. Elwenspoek, J. J. Kelly, An electrochemical microactuator: principle and first results, J. Microelectromech. Syst. 5 (1996) 2-9.

[7] M. Winter, J. O. Besenhard, M. E. Spahr, P. Novak, Insertion electrode materials for rechargeable lithium batteries, Adv. Mater. 10 (1998) 725-763.

[8] K. Takada, S. Kondo, Electrochemical actuator with silver vanadium bronzes, Solid State Ionics. 53-56 (1992) 339-342.

[9] G. Gu , M. Schmid , P.W. Chiu , A. Minett, J. Fraysse, G. T. Kim, S Roth, M Kozlov, E Muñoz, R. H. Baughman, $\mathrm{V}_{2} \mathrm{O}_{5}$ nanofibre sheet actuators, Nat. Materials. 2 (2003) 316-319. 
[10] Y. Koyama, T. E. Chin, U. Rhyner, R. K. Holman, S. R. Hall, and Y. M. Chiang, Harnessing the actuation potential of solid-state intercalation compounds, Adv. Func. Mater. 16(2006) 492-498.

[11] T. E. Chin, U. Rhyner, Y. Koyama, S. R. Hall, and Y. M. Chiang, Lithium rechargeable batteries as electromechanical actuators, Electrochem. Solid-State Lett. 9 (2006) A134-A138.

[12] J.N. Reimers, J.R. Dahn, Electrochemical and in situ X-ray diffraction studies of lithium intercalation in $\mathrm{Li}_{\mathrm{x}} \mathrm{CoO}_{2}$, J. Electrochem. Soc. 139 (1992) 2091-2097.

[13] J. B. Bates, N. J. Dudney, B. J. Neudecker, F. X. Hart, H. P. Jun, S. A. Hackney, Preferred orientation of polycrystalline $\mathrm{LiCoO}_{2}$ films, J. Electrochem. Soc. 147 (2000) 59-70.

[14] T. Nakamura, and A. Kajiyama, Synthesis of $\mathrm{LiCoO}_{2}$ particles with uniform size distribution using hydrothermally precipitated $\mathrm{Co}_{3} \mathrm{O}_{4}$ fine particles, Solid State Ionics, , 123 (1999) 95-101.

[15] H. Zhang, P.J. Baker and P.S. Grant, Fabrication and electrical properties of bulk textured $\mathrm{LiCoO}_{2}$, J. Am. Ceram. Soc. 93 (2010) 1856-1859.

[16]T. Takenaka and K. Sakata, Grain orientation and electrical properties of hot-forged $\mathrm{Bi}_{4} \mathrm{Ti}_{3} \mathrm{O}_{12}$ ceramics, Jpn. J. Appl. Phys., 19 (1980) 31-39.

[17] A. Clémençon, A.T. Appapillai, S. Kumar, Y. Shao-Horn, Atomic force microscopy studies of surface and dimensional changes in $\mathrm{Li}_{\mathrm{x}} \mathrm{CoO}_{2}$ crystals during lithium de-intercalation, Electrochimica Acta., 52 (2007) 4572-4580.

[18] J. H. Lee, H. M. Lee, S. Ahn, Battery dimensional changes occurring during charge/discharge cycles-thin rectangular lithium ion and polymer cells, J. Power Sources. 119-121 (2003) 833-837

[19] X. Wang,Y. Sone, S. Kuwajima, In situ investigation of the volume change in Li-ion cell with charging and discharging, J. Electrochem. Soc. 151 (2004) A273-A280

[20] M. Wakihara, Recent developments in lithium ion batteries, Mater. Sci. Engin. R. 33 (2001) 109134.

[21] G. G. Amatucci, J.M. Tarascon, L.C. Klein, Cobalt dissolution in $\mathrm{LiCoO}_{2}$-based non-aqueous rechargeable batteries, Solid State lonics. 83 (1996) 167-173.

[22] W. Lai, C. K. Erdonmez, T. F. Marinis, C. K. Bjune, N. J. Dudney, F. Xu, R. Wartena, and Y. M. Chiang, Ultrahigh-energy-density microbatteries enabled by new electrode architecture and micropackaging design, Adv. Mater. 22 (2010) E139-E144

[23] X. Wang, I. Loa, K. Kunc, K. Syassen, M. Amboage, Effect of pressure on the structural properties and Raman modes of $\mathrm{LiCoO}_{2}$, Phys. Rev. B 72 (2005) 224102. 
[24] S. B. Tang, L. Lu and M. O. Lai, Characterization of a $\mathrm{LiCoO}_{2}$ thin film cathode grown by pulsed laser deposition, Philosophical Magazine. 85 (2005) 2831-2842.

[25] B. Su, D. Zhang, T. W. Button, Micropatterning of fine scale ceramic structures, J. Mater. Sci., $2002,37,3123-3126$.

[26] A. Schneider, B. Su, T. W. Button, L. Singleton, O. Wilhelmi, S. E. Huq, P. D. Prewett, R. A. Lawes, Comparison of PMMA and SU-8 resist moulds for embossing of PZT to produce highaspect-ratio microstructures using LIGA process, Microsystem Technologies. 8 (2002) 88-92.

[27] Y-M. Chiang, M. J. Cima, T.E. Chin, Electrochemical microactuators, US patent, US7,999,435 B2, USA, 2011

[28] A. Nisar, N. Afzulpurkar, B. Mahaisavariya, A. Tuantranont, Sens. Actuators B: Chem., 130 (2008) 917-942

\section{Biographies}

Hongtao Zhang obtained his $\mathrm{PhD}$ from Queen Mary University of London in 2006. After graduation he worked as a research fellow in group of "Processing of Advanced Materials", Department of Materials, University of Oxford. His research interest is energy materials, such as lithium ion batteries and nuclear materials.

Patrick Grant is currently Cookson Professor of Materials at Oxford University. His research activities are focused on novel materials processed through liquid droplet, such as spray forming of advanced superalloy for aerospace industry and wet powder spraying for energy storage materials. 


\section{Figure captions}

Fig. 1 Schematic diagram showing the structure of the intercalation compounds based microactuator

Fig. 2: Side view of the $\mathrm{LiCoO}_{2}$ post arrays fabricated by dicing.

Fig. 3 A photograph of the in-situ strain monitoring system

Fig. 4 XRD patterns of $\mathrm{LiCoO}_{2}$ : (a) as-supplied powder, and (b) hot pressed bulk ceramic with the surface perpendicular to the hot-pressing direction.

Fig. $5 \mathrm{SEM}$ micrographs of the textured $\mathrm{LiCoO}_{2}$ ceramics from surface (a) perpendicular and (b) parallel to the hot-pressing direction.

Fig. 6 Electrochemical actuation of the $\mathrm{LiCoO}_{2}$ pillar array microactuator under two different charging/discharging protocols: (a) the effect of $\mathrm{CV}$ charging and $\mathrm{CC}$ discharging on the actuation strain and microactuator voltage; (b) the effect of CC charging and $\mathrm{CC}$ discharging on the actuation strain and microactuator voltage.

Fig. 7 Actuation stress and strain of electrochemical microactuators in this study, compared with other actuation technologies. 


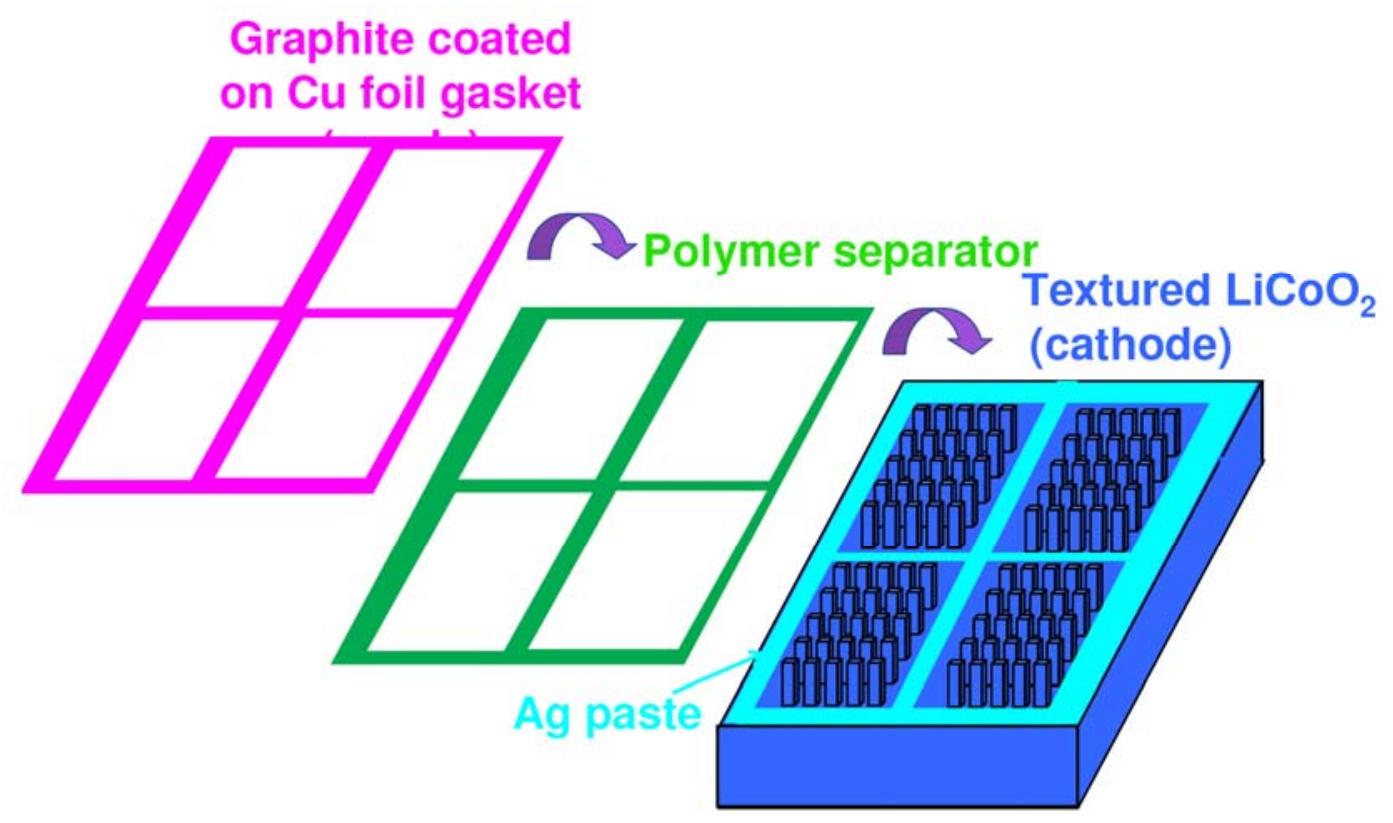

Fig. 1

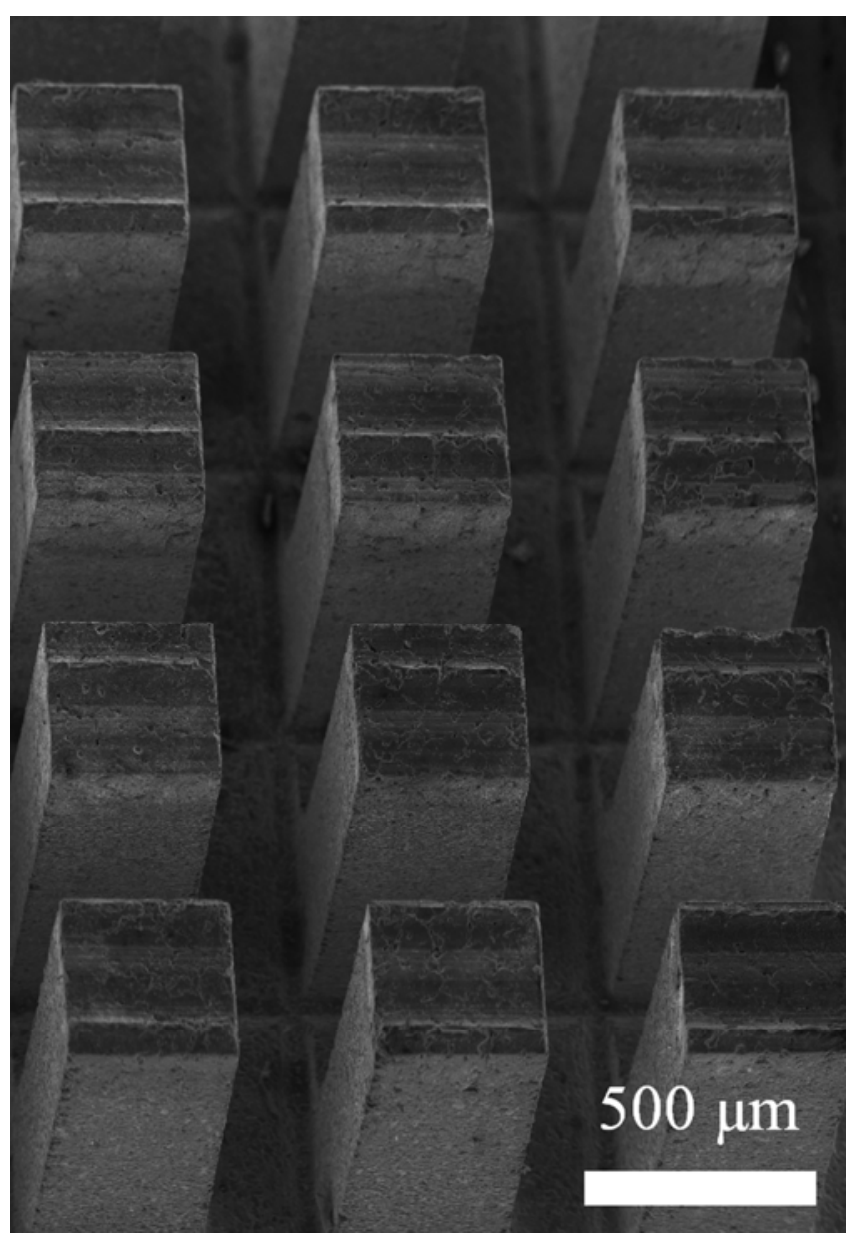

Fig. 2 


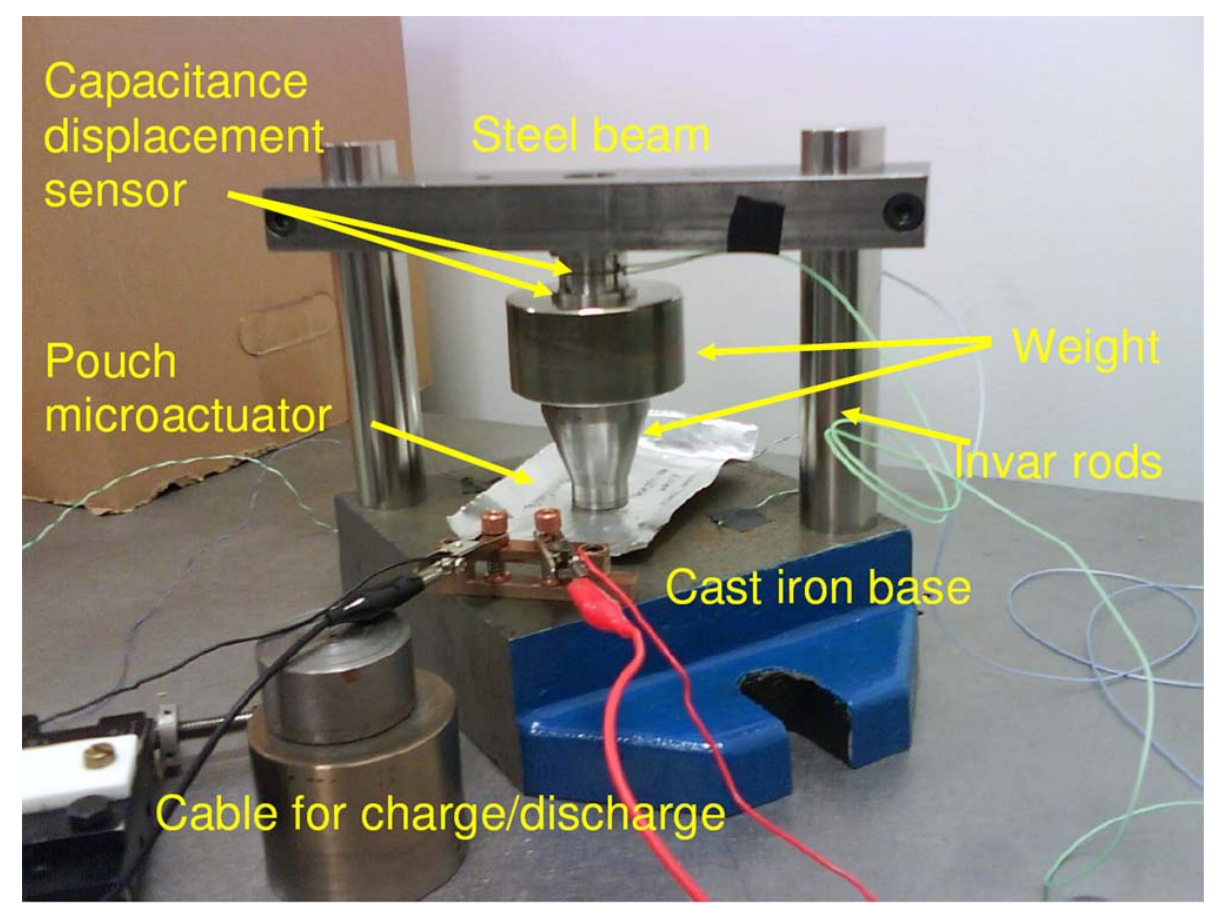

Fig. 3

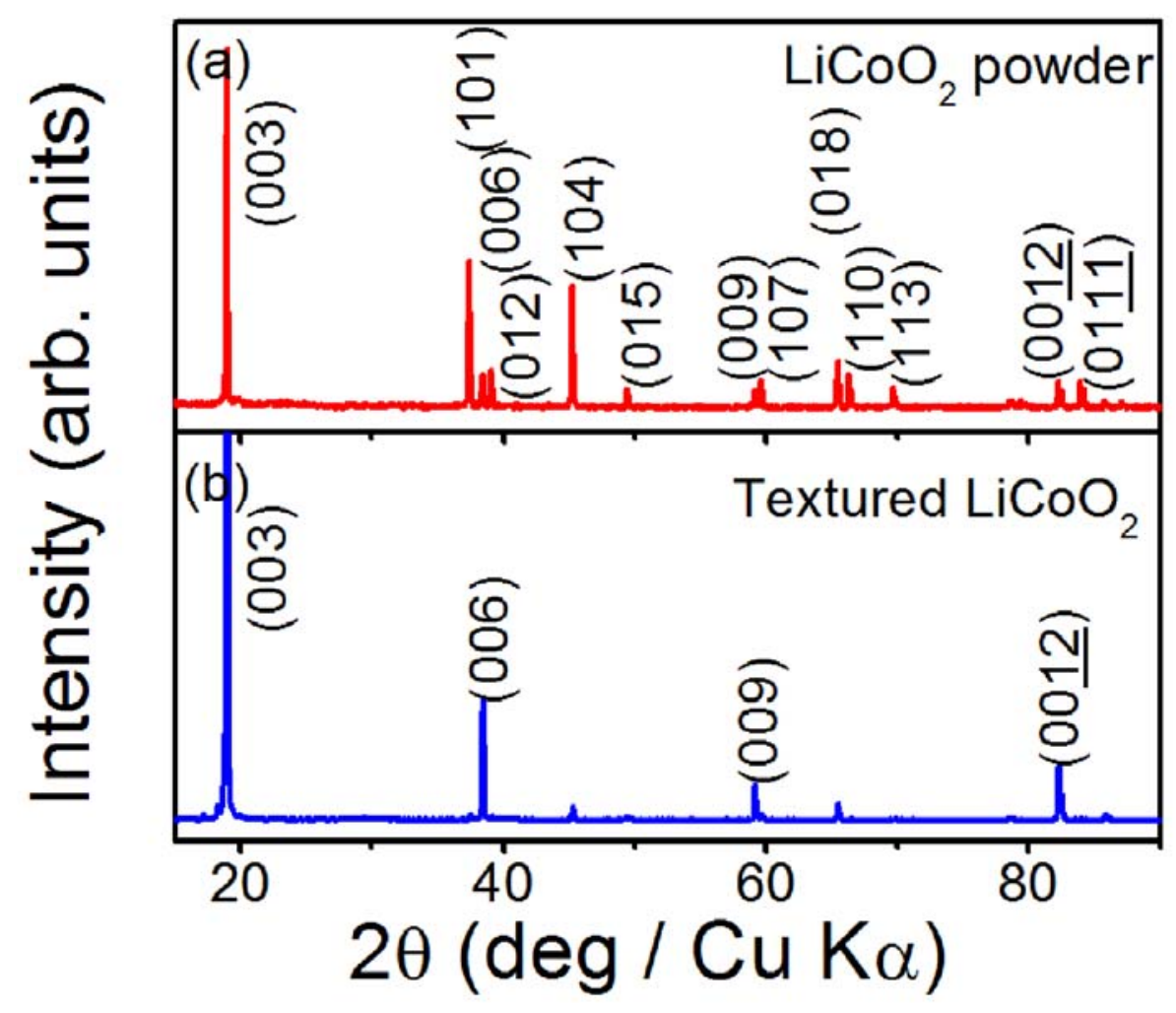

Fig. 4 

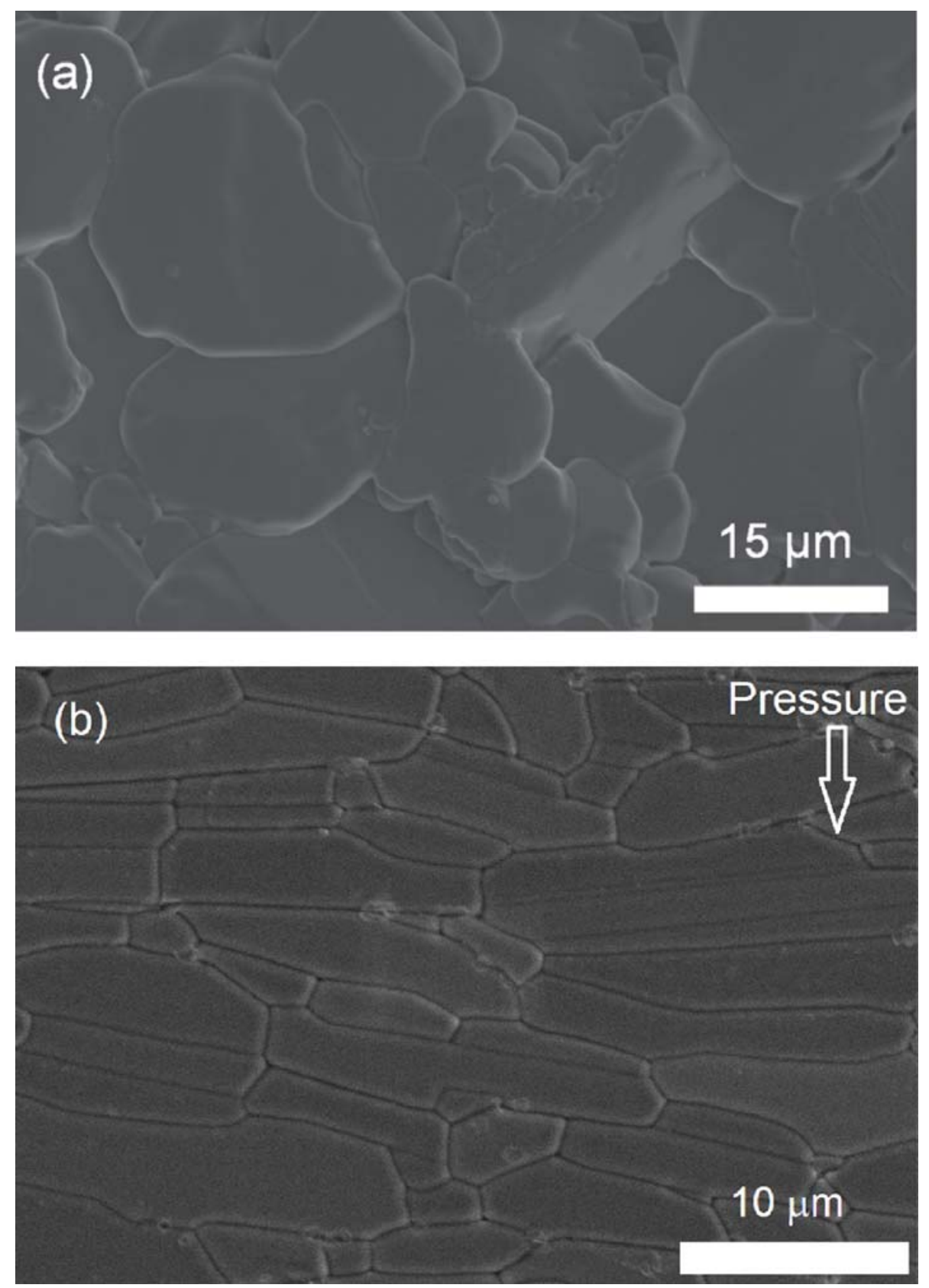

Fig. 5 

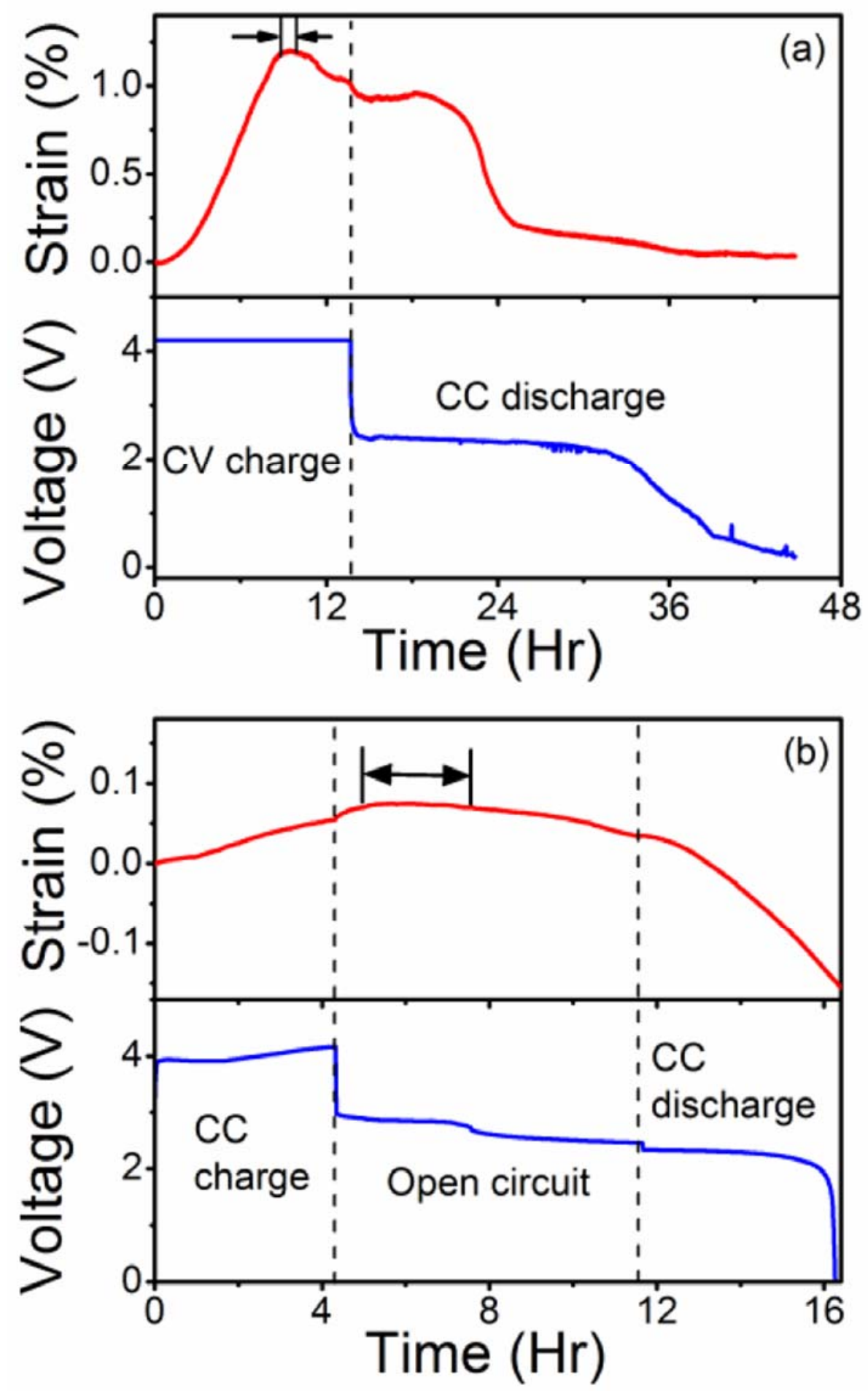

Fig. 6 


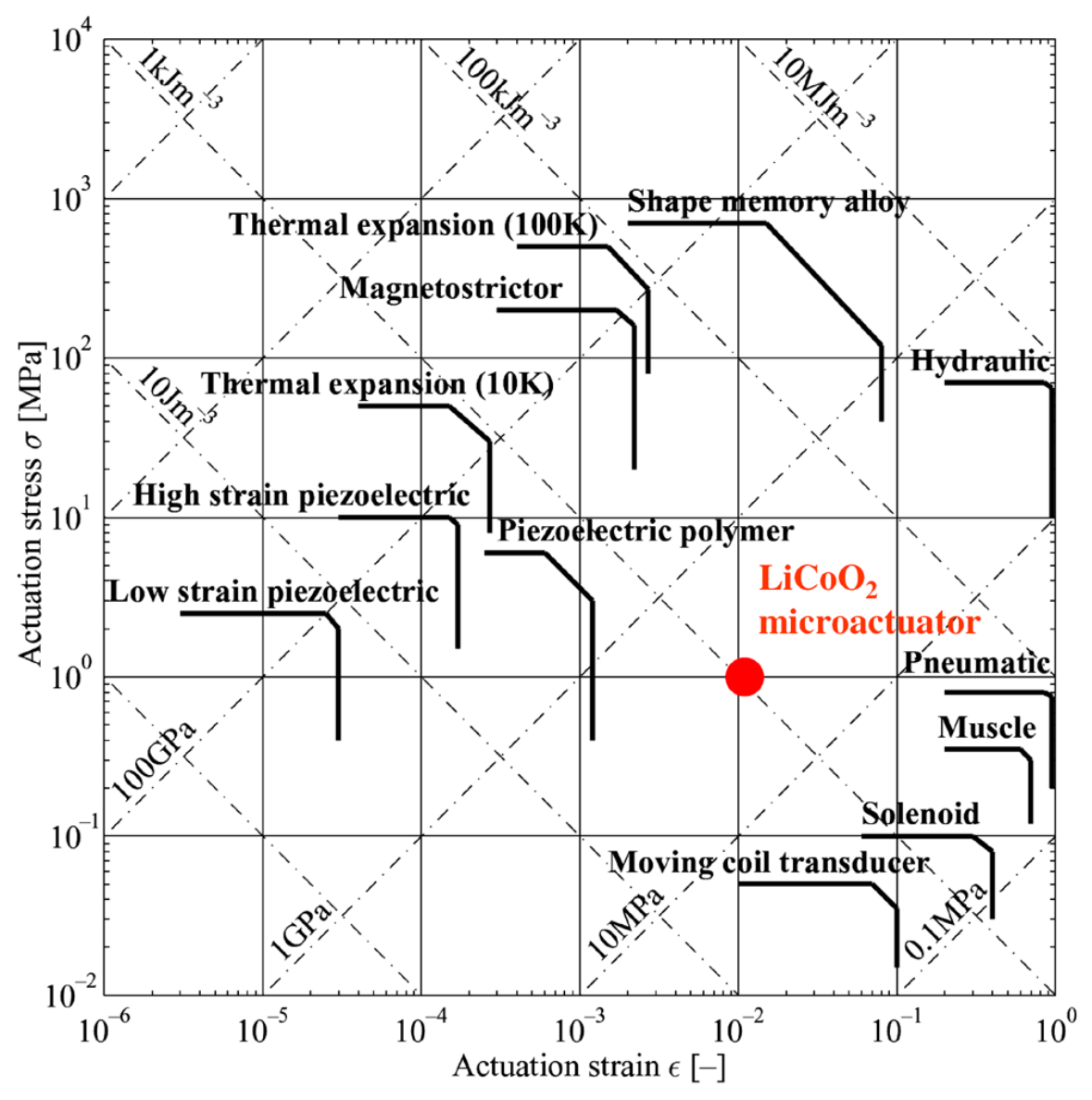

Fig. 7 